\title{
Comparison of differentiated thyroid carcinoma recurrence and its clinical features in children of different ages
}

\author{
Bin $\mathrm{Ye}^{1, *}$, Jun Shi ${ }^{1, *}$, Chenling Shen ${ }^{2, *}$, Longhao Wang ${ }^{1}$, Haixia Hu${ }^{1}$, Yan Ma ${ }^{1}$, Quan \\ Wang $^{1}$, Jingrong Lu ${ }^{1}$, Guangjun $\mathbf{Y u}^{2}$ and Mingliang Xiang ${ }^{1}$ \\ ${ }^{1}$ Department of Otolaryngology Head and Neck Surgery, Xinhua Hospital, Shanghai Jiao Tong University School of Medicine, \\ Shanghai, China \\ ${ }^{2}$ Shanghai Jiao Tong University School of Medicine, Shanghai, China \\ *These authors have contributed equally to this work \\ Correspondence to: Mingliang Xiang, email: mingliangxiang@163.com \\ Guangjun Yu, email: Gjyu@shchildren.com.cn \\ Jingrong Lu, email: Ivjingrong@hotmail.com \\ Keywords: differentiated thyroid carcinoma, recurrence, recurrence-free survival, pediatrics \\ Abbreviations: ATA: American Thyroid Association; DTC: differentiated thyroid carcinoma; TNM: tumor-node-metastasis \\ Received: January 02, $2017 \quad$ Accepted: May 03, $2017 \quad$ Published: May 26, 2017 \\ Copyright: Ye et al. This is an open-access article distributed under the terms of the Creative Commons Attribution License 3.0 \\ (CC BY 3.0), which permits unrestricted use, distribution, and reproduction in any medium, provided the original author and source \\ are credited.
}

\section{ABSTRACT}

The prevalence of differentiated thyroid carcinoma (DTC) in children is increasing. However, the clinical features and recurrence of DTC in children in different age groups, especially those less than 14 years old, are not well studied. We retrospectively investigated 73 children diagnosed with DTC in our hospital between January 1998 and July 2014. Data were reviewed for different age groups based on the age at initial

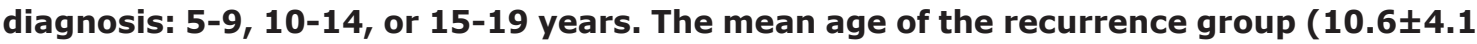
years) was lower than that of the non-recurrence group $(12.6 \pm 6.2$ years; $P=0.004)$. The main symptom at initial diagnosis was local invasion in the recurrence group, but was thyroid nodules in the non-recurrence group $(P<0.001)$. The recurrence and non-recurrence groups did not differ in TNM stage or risk level. However, according to our age classification, the American Thyroid Association pediatric risk level was significantly different in three age groups $(P=0.024)$. The $D T C$ recurrence rate in each age group decreased as the age of the children increased $(P=0.011)$. Thus, a high risk of recurrence and a high proportion of local invasion cases were observed in the youngest age group, suggesting that younger age is an important risk factor for DTC recurrence in children.

\section{INTRODUCTION}

The proportion of newly diagnosed differentiated thyroid carcinoma (DTC) cases is increasing among individuals under the age of 20 [1-3]. The symptoms of DTC in children are not usually typical upon initial diagnosis; while DTC may present as a neck mass (with or without a thyroid lesion) in some children, in others, DTC may not even be diagnosed until the discovery of distant metastases. Children with DTC have a high degree of extrathyroid extension and high rates of distant metastasis and recurrence [4-6]; nonetheless, the prognosis for these patients is usually good, and disease-specific death rarely occurs [7-9].

A more aggressive presentation and higher distant metastasis rate have been observed in pre-pubertal children than in adolescents with DTC [5]. However, previous studies of DTC have included considerable proportions of adolescents [1, 10-13]. The clinical features of children with DTC, especially children less than 10 years old, are still not well understood. Indeed, according to 2015 guidelines, the specific circumstances of each age group 
of DTC patients have not yet been explained in detail, especially for younger age groups [14].

Thus, in the present study, 73 children with DTC treated in our hospital were retrospectively evaluated by age group. The same diagnostic and therapeutic techniques were employed for all subjects. We compared the age groups in terms of their clinical presentation, TNM stage, risk level of recurrence, and other characteristics.

\section{RESULTS}

In total, 73 children with DTC were included: 54 cases without recurrence and 19 cases with recurrence. The mean age of the recurrence group was $10.6 \pm 4.1$ years, which was lower than that of the non-recurrence group (12.6 \pm 6.2 years; $P=0.004)$. The main symptom in the recurrence group at initial diagnosis was local invasion (13 cases, 68.4\%) $(P<0.001)$, while the main initial symptom in the non-recurrence group was thyroid nodules (35 cases, 65.0\%) $(P<0.001)$.

The gender proportions of the two groups were similar, with both groups having slightly more females than males. Significant differences were not observed in tumor size, thyroid nodule number and cervical lymph node metastasis between the recurrence and non-recurrence groups (Table 1). When Tumor-NodeMetastasis (TNM) staging was performed according to the 2015 American Joint Committee on Cancer guidelines, the two groups did not differ significantly in TNM stage. The numbers (percentages) of T1a, T1b, T2, and N0 tumors in the recurrence group were $1(10.5 \%), 4(21.1 \%), 8$ $(42.1 \%)$, and $11(57.9 \%)$, respectively, while the numbers (percentages) in the non-recurrence group were $9(16.7 \%)$, $9(16.7 \%), 23(42.6 \%)$, and $23(42.6 \%)$, respectively. The risk levels also did not differ significantly between the recurrence and non-recurrence groups. In the recurrence group, there were $8(42.1 \%), 3(15.8 \%)$ and $8(42.1 \%)$ low-, intermediate- and high-risk cases, respectively, and in the non-recurrence group, there were 21 (38.9\%), 15 (27.8\%), and 18 (33.3\%) low-, intermediate- and high-risk cases, respectively (Table 1).

Differences were not observed in operative procedures, postoperative complications or pathology between the two groups (Table 1). Pathological classifications of papillary, papillary with follicular variant, follicular, and medullary carcinoma did not differ significantly between the two groups (Table 1). The frequency of radioiodine $\left(\mathrm{I}^{131}\right)$ and L-thyroxine treatment was slightly lower in the recurrence group than in the non-recurrence group, though the difference was not significant. In addition, the frequency of lung metastasis in the recurrence group was not significantly different from that in the non-recurrence group (Table 1).

Next, the 73 children with DTC were divided into three groups with five-year age intervals, according to their age at diagnosis. Among them, 21 patients were
5-9 years old, 16 patients were 10-14 years old, and 36 patients were 15-19 years old. The follow-up times for the age groups were 70.6 $\pm 27.6,59.3 \pm 37.4$, and $53.0 \pm 30.9$ months, respectively (Table 2).

We then determined the recurrence intervals for all the age groups, and found that the average recurrence times for the 5-9-, 10-14- and 15-19-year-old groups were $31 \pm 33.11,31.4 \pm 19.46$ and $25 \pm 16.85$ months, respectively. The number of recurrent cases was $9(42.9 \%)$ in the 5-9-year-old group, $5(31.3 \%)$ in the 10-14-yearold group, and $5(13.9 \%)$ in the 15-19-year-old group. The recurrence rates differed significantly among the age groups $(P=0.046)$ (Table 2$)$.

The ratios of males to females in the three groups were $12: 9,5: 11$, and $6: 30$, respectively, revealing that the proportion of males was highest in the youngest group. Initial thyroid nodule symptoms were more common in the oldest group of children with DTC $(P=0.044)$, while in the younger age groups (5-9 years and 10-14 years), cervical masses were often found during routine physical examinations. The 5-9-year-old children with DTC often presented with local invasion ( 8 cases, $38.1 \%$ ), including that of the muscle, recurrent laryngeal nerve and trachea, although the local invasion rate did not differ significantly among the groups. The tumor sizes and pathological types were similar across the age groups.

Although statistically significant differences were not observed for $\mathrm{T}, \mathrm{N}$ and $\mathrm{M}$ stages among the age groups, the proportion of T4a-stage cases was higher in the 5-9-year-old group than in the other age groups. The number of high-risk patients was significantly higher in the 5-9-year-old group than in the other two groups $(\mathrm{P}<0.05)$, and the proportion of high-risk patients in each age group decreased with age (Table 2 ).

The age groups did not differ significantly in terms of surgical procedure, postoperative complications, postoperative $\mathrm{I}^{131}$ proportion, L-thyroxine therapy, or lung metastasis. The recurrence-free survival times of the three groups did not differ significantly (Figure 1). During the follow-up period, no deaths were observed after surgery and $\mathrm{I}^{131}$ therapy, though cases of lung metastasis were recorded.

\section{DISCUSSION}

Differences in tumor manifestation, neck recurrence and lung metastasis have been established between children and adults with DTC $[15,16]$, and differences have also been reported between pre-pubertal children and adolescents with DTC $[5,17]$. Considering the increasing incidence of DTC in children in recent years, we analyzed the clinical features of children who had experienced DTC recurrence, and focused on the trends in age groups of five-year intervals.

The children in the non-recurrence group were older than those in the recurrence group (mean ages: 
Table 1: Characteristics of children in the recurrence and non-recurrence groups

\begin{tabular}{|c|c|c|c|}
\hline \multirow[t]{2}{*}{ Characteristic } & $\begin{array}{c}\text { Non-recurrence } \\
\text { group }\end{array}$ & Recurrence group & \multirow[t]{2}{*}{$\mathbf{P}$} \\
\hline & $\mathrm{n}=54$ & $n=19$ & \\
\hline Age at diagnosis (years, mean \pm SD) & $12.6 \pm 6.24$ & $10.6 \pm 4.1$ & 0.004 \\
\hline Sex (male:female) & $17: 37(31.5 \%$ male $)$ & $6: 13(31.6 \%$ male $)$ & NS \\
\hline \multicolumn{4}{|l|}{ Status at diagnosis } \\
\hline Thyroid nodules & $35(65.0 \%)$ & $7(36.8 \%)$ & 0.0003 \\
\hline Cervical mass & $23(42.6 \%)$ & $14(73.7 \%)$ & 0.835 \\
\hline Local invasion & $1(1.9 \%)$ & $13(68.4 \%)$ & $9 \times 10^{-6}$ \\
\hline \multicolumn{4}{|l|}{ Primary tumor } \\
\hline Mean size $(\mathrm{cm}$, mean $\pm \mathrm{SD})$ & $2.2 \pm 1.2$ & $2.4 \pm 1.4$ & \multirow[t]{3}{*}{ NS } \\
\hline Unilateral thyroid nodule & $37(68.5 \%)$ & $15(78.9 \%)$ & \\
\hline Multifocality & $16(29.6 \%)$ & $3(15.8 \%)$ & \\
\hline LN metastases & $26(48.1 \%)$ & $5(26.3 \%)$ & \multirow[t]{3}{*}{ NS } \\
\hline Ipsilateral & $18(33.3 \%)$ & $5(26.3 \%)$ & \\
\hline Bilateral & $8(14.8 \%)$ & 0 & \\
\hline Lung metastases & $4(7.4 \%)$ & $1(5.3 \%)$ & NS \\
\hline \multicolumn{4}{|l|}{ Tumor stage } \\
\hline T1a & $9(16.7 \%)$ & $1(10.5 \%)$ & \multirow[t]{6}{*}{ NS } \\
\hline $\mathrm{T} 1 \mathrm{~b}$ & $9(16.7 \%)$ & $4(21.1 \%)$ & \\
\hline $\mathrm{T} 2$ & $23(42.6 \%)$ & $8(42.1 \%)$ & \\
\hline $\mathrm{T} 3$ & $4(5.55 \%)$ & $2(10.5 \%)$ & \\
\hline $\mathrm{T} 4 \mathrm{a}$ & $7(13.0 \%)$ & $4(21.1 \%)$ & \\
\hline $\mathrm{T} 4 \mathrm{~b}$ & $2(3.7 \%)$ & 0 & \\
\hline \multicolumn{4}{|l|}{ N stage } \\
\hline N0 & $23(42.6 \%)$ & $11(57.9 \%)$ & \multirow[t]{3}{*}{ NS } \\
\hline N1a & $16(29.6 \%)$ & $3(15.8 \%)$ & \\
\hline N1b & $15(27.8 \%)$ & $5(26.3 \%)$ & \\
\hline \multicolumn{4}{|l|}{ M stage } \\
\hline M0 & $50(92.6 \%)$ & $17(89.5 \%)$ & \multirow[t]{2}{*}{ NS } \\
\hline M1 & $4(7.4 \%)$ & $2(10.5 \%)$ & \\
\hline \multicolumn{4}{|l|}{ ATA pediatric risk level } \\
\hline Low & $21(38.9 \%)$ & $8(42.1 \%)$ & \multirow[t]{3}{*}{ NS } \\
\hline Intermediate & $15(27.8 \%)$ & $3(15.8 \%)$ & \\
\hline High & $18(33.3 \%)$ & $8(42.1 \%)$ & \\
\hline \multicolumn{4}{|l|}{ Surgical procedure } \\
\hline Unilateral lobectomy & $7(13.0 \%)$ & $2(10.5 \%)$ & \multirow[t]{2}{*}{ NS } \\
\hline $\begin{array}{l}\text { Unilateral lobectomy with IV region } \\
\text { dissection }\end{array}$ & $14(25.9 \%)$ & $6(31.6 \%)$ & \\
\hline
\end{tabular}

(Continued) 


\begin{tabular}{|c|c|c|c|}
\hline \multirow[t]{2}{*}{ Characteristic } & $\begin{array}{l}\text { Non-recurrence } \\
\text { group }\end{array}$ & Recurrence group & $\mathbf{P}$ \\
\hline & $n=54$ & $n=19$ & \\
\hline TT with IV region dissection & $33(61.1 \%)$ & $11(57.9 \%)$ & \\
\hline Lateral cervical lymph node dissection & & & NS \\
\hline Ipsilateral & $18(33.3 \%)$ & $6(31.6 \%)$ & \\
\hline Bilateral & $7(13.0 \%)$ & $2(10.5 \%)$ & \\
\hline Tracheotomy and other procedure & $1(1.9 \%)$ & 0 & \\
\hline Histology & & & NS \\
\hline Papillary & $39(72.2 \%)$ & $16(84.2 \%)$ & \\
\hline Papillary with follicular variant & $8(14.8 \%)$ & $1(5.3 \%)$ & \\
\hline Follicular & $6(11.1 \%)$ & 0 & \\
\hline Medullary & $1(1.9 \%)$ & $2(10.5 \%)$ & \\
\hline Postoperative complications & & & NS \\
\hline Recurrent laryngeal nerve damage & $4(7.4 \%)$ & $1(5.3 \%)$ & \\
\hline Hypocalcaemia & $3(5.55 \%)$ & $2(10.5 \%)$ & \\
\hline Postoperative radioiodine treatment & $39(72.2 \%)$ & $11(57.9 \%)$ & NS \\
\hline LT-4 replacement & $45(83.3 \%)$ & $13(68.4 \%)$ & NS \\
\hline \multicolumn{4}{|l|}{ Follow-up status } \\
\hline Distant or regional metastasis after treatment & $8(14.8 \%)$ & $6(31.6 \%)$ & NS \\
\hline
\end{tabular}

NS: not significant; LN: lymph nodes; TT: total thyroidectomy. The TNM classification system and ATA pediatric risk levels were based on the Guidelines for Children with Thyroid Nodules and Differentiated Thyroid Cancer [14].

$12.6 \pm 6.2$ and 10.6 \pm 4.1 years, respectively), Moreover, the frequency of recurrence varied among the age groups, being $42.9 \%$ in the $5-9$-year-old group, $31.3 \%$ in the $10-14$-year-old group, and $13.9 \%$ in the 15 -19-yearold group. This observation suggests that those initially diagnosed at a younger age may be more prone to tumor recurrence. Therefore, regular follow-ups and examinations should be emphasized for younger children with DTC [18].

When we performed TNM staging and risk stratification according to the 2015 American Joint Committee on Cancer recommendations [19], we did not observe significant differences between the recurrence and non-recurrence groups in TNM stage or risk level. The total percentage of $\mathrm{T} 1 \mathrm{a}, \mathrm{T} 1 \mathrm{~b}$, and $\mathrm{T} 2$ tumors was greater than $50 \%$, and the percentage of $\mathrm{N} 0$ tumors was close to $50 \%$ in non-recurrence group. The low-risk level accounted for nearly $40 \%$ of children in both the recurrence and non-recurrence groups (Table 1), which suggests that nearly half of the recurrent cases were low-risk when they were initially diagnosed. Thus, in the present study, the ATA-recommended risk factors examined during the initial diagnosis did not appear to be sufficient to predict the risk of recurrence. Further research should focus on identifying new strategies for assessing recurrence risk.

When we studied the clinical characteristics of children with DTC grouped at five-year intervals, we found that the proportion of males decreased with increasing age, whereas the proportion of females increased. Interestingly, the recurrence rate of each group decreased with increasing age. The proportions of males and females in the three groups were 12:9, 5:11, and 6:30 (Table 2), but the recurrence rates were $42.9 \%, 31.3 \%$, and $13.9 \%$ (Table 2). This trend suggests that the DTC recurrence rate was related to the proportion of males.

In the 15-19-year-old adolescent group, the majority of patients were diagnosed with thyroid nodules ( 24 cases, $68.8 \%$ ), whereas in younger children with DTC (5-9- and 10-14-year-olds), the majority of patients were diagnosed with cervical masses $(66.7 \%$ and $68.8 \%$, respectively). The rate of local invasion of the striated muscle and recurrent laryngeal nerve was higher in the 5-9-year-old group than in the other age groups, although the difference was not significant $(\mathrm{p}=0.091)$; thus, the proportion of highrisk cases was greater in this group $(P=0.024)$ (Table 2). Such age-related clinical manifestations may be due to age-specific metabolism and genetic factors in younger 
Table 2: Differences in TNM staging and risk level among the age groups of children with DTC

\begin{tabular}{|c|c|c|c|c|}
\hline \multirow[t]{3}{*}{ Characteristic } & \multicolumn{4}{|c|}{ Age at diagnosis (years) } \\
\hline & \multirow{2}{*}{$\begin{array}{c}5-9 \\
n=21\end{array}$} & \multirow{2}{*}{$\frac{10-14}{n=16}$} & \multirow{2}{*}{$\begin{array}{c}15-19 \\
n=36\end{array}$} & \multirow[t]{2}{*}{$\mathbf{P}$} \\
\hline & & & & \\
\hline Age at diagnosis (years, mean \pm SD) & $7.5 \pm 1.4$ & $11.8 \pm 1.6$ & $16.9 \pm 1.4$ & 0.000 \\
\hline Sex (male:female) & $\begin{array}{c}12: 9(57.1 \% \\
\text { male })\end{array}$ & $\begin{array}{c}5: 11(31.3 \% \\
\text { male })\end{array}$ & $\begin{array}{c}6: 30(16.7 \% \\
\text { male })\end{array}$ & 0.007 \\
\hline \multicolumn{5}{|l|}{ Status at diagnosis } \\
\hline Thyroid nodules & $9(42.9 \%)$ & $9(56.3 \%)$ & $24(68.8 \%)$ & 0.044 \\
\hline Cervical mass & $14(66.7 \%)$ & $11(68.8 \%)$ & $12(33.3 \%)$ & 0.161 \\
\hline Local invasion & $8(38.1 \%)$ & $1(6.3 \%)$ & $5(13.9 \%)$ & 0.091 \\
\hline \multicolumn{5}{|l|}{ Primary tumor } \\
\hline Mean size $(\mathrm{cm}$, mean $\pm \mathrm{SD})$ & $2.4 \pm 1.4$ & $2.4 \pm 0.7$ & $2.1 \pm 1.3$ & NS \\
\hline Histology & & & & NS \\
\hline Papillary & $16(76.2 \%)$ & $13(81.2 \%)$ & $26(72.2 \%)$ & \\
\hline Papillary with follicular variant & $2(9.5 \%)$ & $2(12.5 \%)$ & $5(13.9 \%)$ & \\
\hline Follicular & $2(9.5 \%)$ & 0 & $4(11.1 \%)$ & \\
\hline Medullary & $1(4.8 \%)$ & $1(6.25 \%)$ & $1(2.8 \%)$ & \\
\hline Tumor stage & & & & NS \\
\hline T1a & $1(4.8 \%)$ & $1(6.3 \%)$ & $9(25 \%)$ & \\
\hline $\mathrm{T} 1 \mathrm{~b}$ & $4(19.0 \%)$ & $3(18.8 \%)$ & $6(16.7 \%)$ & \\
\hline $\mathrm{T} 2$ & $8(38.1 \%)$ & $11(68.8 \%)$ & $12(33.3 \%)$ & \\
\hline T3 & $1(4.8 \%)$ & $1(6.3 \%)$ & $3(8.3 \%)$ & \\
\hline $\mathrm{T} 4 \mathrm{a}$ & $6(28.6 \%)$ & 0 & $5(13.9 \%)$ & \\
\hline $\mathrm{T} 4 \mathrm{~b}$ & $1(4.8 \%)$ & 0 & $1(2.8 \%)$ & \\
\hline N stage & & & & NS \\
\hline No & $9(42.6 \%)$ & $7(43.8 \%)$ & $18(50.0 \%)$ & \\
\hline N1a & $4(19.0 \%)$ & $4(25.0 \%)$ & $11(30.6 \%)$ & \\
\hline $\mathrm{N} 1 \mathrm{~b}$ & $8(38.1 \%)$ & $5(31.2 \%)$ & $7(19.4 \%)$ & \\
\hline M stage & & & & NS \\
\hline M0 & $19(90.5 \%)$ & $13(81.3 \%)$ & $35(97.2 \%)$ & \\
\hline M1 & $2(9.5 \%)$ & $3(18.8 \%)$ & $1(2.8 \%)$ & \\
\hline ATA pediatric risk level & & & & 0.024 \\
\hline Low & $6(28.6 \%)$ & $6(37.5 \%)$ & $17(47.2 \%)$ & $0.011 *$ \\
\hline Intermediate & $2(9.5 \%)$ & $4(25.0 \%)$ & $12(33.3 \%)$ & \\
\hline High & $13(61.9 \%)$ & $6(37.5 \%)$ & $7(19.4 \%)$ & \\
\hline Surgical procedure & & & & NS \\
\hline Unilateral lobectomy & $3(14.3 \%)$ & $2(12.5 \%)$ & $4(11.1 \%)$ & \\
\hline Unilateral lobectomy with IV region dissection & $3(14.3 \%)$ & $5(31.3 \%)$ & $12(33.3 \%)$ & \\
\hline
\end{tabular}




\begin{tabular}{|c|c|c|c|c|}
\hline \multirow[t]{3}{*}{ Characteristic } & \multicolumn{4}{|c|}{ Age at diagnosis (years) } \\
\hline & $5-9$ & $10-14$ & 15-19 & $\mathbf{P}$ \\
\hline & $\mathrm{n}=\mathbf{2 1}$ & $n=16$ & $\mathrm{n}=\mathbf{3 6}$ & \\
\hline TT with IV region dissection & $15(71.4 \%)$ & $9(56.3 \%)$ & $20(27.4 \%)$ & \\
\hline Lateral cervical lymph node dissection & & & & NS \\
\hline Ipsilateral & $7(33.3 \%)$ & $5(31.3 \%)$ & $12(33.3 \%)$ & \\
\hline Bilateral & $3(4.3 \%)$ & $3(18.8 \%)$ & $3(8.3 \%)$ & \\
\hline Tracheotomy and other procedure & $1(4.8 \%)$ & 0 & 0 & NS \\
\hline Postoperative complications & & & & NS \\
\hline Recurrent laryngeal nerve damage & $2(9.5 \%)$ & $1(6.3 \%)$ & $2(5.5 \%)$ & \\
\hline Hypocalcaemia & $2(9.5 \%)$ & $1(6.3 \%)$ & $2(5.5 \%)$ & \\
\hline Postoperative radioiodine treatment & $11(52.4 \%)$ & $9(56.3 \%)$ & $24(66.7 \%)$ & NS \\
\hline LT-4 replacement & $17(80.1 \%)$ & $13(81.3 \%)$ & $25(69.4 \%)$ & NS \\
\hline Median follow-up, months (range) & $62(36-120)$ & $45(18-126)$ & $48(17-132)$ & \\
\hline \multicolumn{5}{|l|}{ Follow-up status } \\
\hline Distant or regional metastasis after treatment & $5(23.8 \%)$ & $5(31.3 \%)$ & $4(11.1 \%)$ & NS \\
\hline Recurrence & $9(42.9 \%)$ & $5(31.3 \%)$ & $5(13.9 \%)$ & 0.046 \\
\hline
\end{tabular}

NS: not significant; LN: lymph nodes; TT: total thyroidectomy. The TNM classification system and ATA pediatric risk levels were based on the Guidelines for Children with Thyroid Nodules and Differentiated Thyroid Cancer [14].

children with DTC, and may contribute to the lack of complaints and delayed findings in younger children $[4,20]$. These findings suggest that more aggressive tumors occur in younger children [21, 22]. Thus, we conclude that a younger age is an important risk factor for DTC recurrence in children $[5,23,24]$.

Recurrence was not observed for the recurrent cases after reoperation to remove the residual thyroid and/ or neck recurrences. For preoperative and postoperative pulmonary metastases, lung metastatic lesions were well-controlled after surgical resection of the lesions and isotope therapy. Although the incidences of local invasion and recurrence were higher in younger children than in older children with DTC, the survival rate was $100 \%$ after our surgical strategy and combined $\mathrm{I}^{131}$ and L-thyroxine treatment in all age groups. During the follow-up period, we did not observe adverse effects of these treatments on the growth and development of these children. This finding was consistent with previously reported results that, despite the serious clinical manifestations of DTC in children, the survival rate in the follow-up period was satisfactory after surgery and $\mathrm{I}^{131}$ and L-thyroxine treatment $[11,25,26,27]$.

In conclusion, younger children with DTC and those with local invasion as an initial symptom were prone to tumor recurrence. Nearly half of the recurrent cases were low-risk when they were initially diagnosed; therefore, follow-up investigations for low-risk children are still necessary. A high proportion of local invasion cases and a high risk of recurrence were observed in the youngest age group; thus, local invasion and younger age represent important risk factors for DTC recurrence in children. Appropriate treatment strategies should be adopted to increase the awareness and follow-up analysis of the risk of DTC in young children.

\section{PATIENTS AND METHODS}

This paper presents a retrospective study of 73 children diagnosed with DTC in our hospital between January 1998 and July 2014. These children were diagnosed and treated by a multidisciplinary team (pediatric otolaryngology head and neck surgeons, pediatric endocrinologists, and nuclear medicine physicians). Data were collected from all patients, including the initial symptoms, TNM stage, risk level, therapy, course, and follow-up results. According to their age at initial diagnosis, the patients were divided into three age groups: the 5-9-year-old group, 10-14-year-old group, and 15-19-year-old group.

We also collected clinical data, including the age, gender, onset of symptoms, ultrasound scans, tumor size, fine-needle aspiration, histological type, invasion of cervical soft tissues, and local and distant metastases (Table 1). TNM stages and risk levels were assessed according to the Management Guidelines for Children 
with Thyroid Nodules and Differentiated Thyroid Cancer, as suggested by the American Thyroid Association (ATA) Guidelines Task Force on Pediatric Thyroid Cancer in 2015 [14] (Table 2).

After ultrasound or fine-needle aspiration, the patients underwent unilateral or bilateral primary surgical resection according to the location of the thyroid lesion. For unilateral DTC, the thyroid gland was unilaterally resected and the ipsilateral level VI lymph node was dissected. Bilateral lobectomy resection was performed for any patient who presented with lymph node metastasis or a local invasion of the capsule, muscle layer, nerve or trachea. For bilateral DTC, bilateral lobectomy and bilateral level VI lymph node dissection were performed. Lateral neck lymph node dissection was performed for neck lymph node lesions. For patients with preoperative and postoperative distant metastases, a series of treatments was considered, including surgery and combined $\mathrm{I}^{131}$ and L-thyroxine treatment.

For ultrasound- or fine-needle-aspirationconfirmed thyroid and lymph node recurrence, the appropriate operation was performed according to the range of recurrent lesions, including the removal of the residual thyroid and selective neck dissection. ${ }^{131}$, thyroid-stimulating hormone and a suppressive dose of L-thyroxine were administered after reoperation.

Data were collected on postoperative complications, including hoarseness and low calcium. Postoperative $\mathrm{I}^{131}$ was used for residual thyroid and distant metastases, and a thyroid-stimulating-hormone-suppressive dose of L-thyroxine was used after surgery. Follow-up investigations were performed every three to six months, including repeat thyroid and cervical ultrasonography, chest X-ray examination and thyroid function tests. For patients appearing to be in remission who presented negative diagnostic whole-body scans, chest X-rays and ultrasounds, and low or normal ranges of serologic thyroglobulin, the repeated inspection interval was extended to every two years.

Disease-free remission was defined by two consecutive negative whole-body scans and ultrasounds and a normal thyroglobulin range. Cases were considered recurrent when evidence of disease was detected in ultrasound scans, thyroglobulin levels were positive, and/ or whole-body scan results were positive.

Postoperative $\mathrm{I}^{131}$ treatment was performed according to the protocols of the Society of Nuclear Medicine and the European Thyroid Cancer Taskforce. The dose was determined from the tumor manifestation, as follows: $30-100 \mathrm{mCi}$ for thyroid capsule invasion, $150 \mathrm{mCi}$ for cervical lymph node metastases, and 175-200 $\mathrm{mCi}$ for distant metastases. The dose of $\mathrm{I}^{131}$ therapy was adjusted according to the child's weight. The simple estimate was calculated as follows: fourfifths of the dose was used for children aged 15-19 years, two-thirds of the dose was used for children

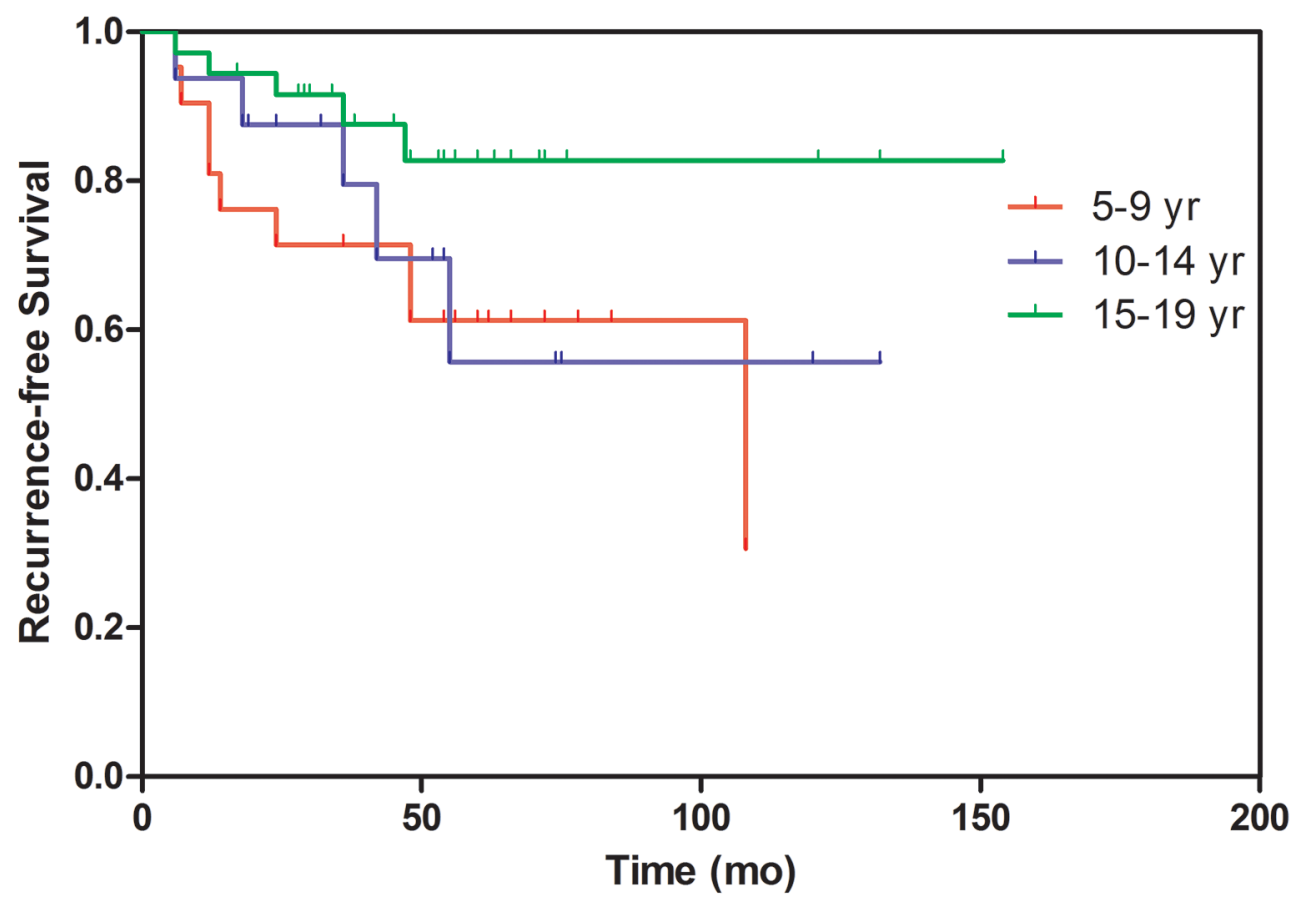

Figure 1: Comparison of the recurrence-free survival times among the age groups. Recurrence-free survival was evaluated by the Kaplan-Meier method. The average recurrence times of the 5-9-, 10-14- and 15-19-year-old age groups were 31 $\pm 33.11,31.4 \pm 19.46$ and $25 \pm 16.85$ months, respectively. The recurrence-free survival times did not differ significantly among the three groups $\left(\mathrm{X}^{2}=4.064\right.$, $\mathrm{P}=0.131$ ). 
aged 10-14 years, and one-third of the dose was used for children aged 5-9 years.

\section{Statistical methods}

The data were statistically analyzed with SPSS software (version. 19.0, SPSS, Chicago, Illinois, USA). All data in each group were analyzed for normality with the Shapiro-Wilk test. The ages and tumor diameters of the recurrence and non-recurrence groups were compared by the Mann-Whitney test. The other parameters were compared between the two groups with a chi-square test. After the patients were divided according to fiveyear age intervals, the ages among the three groups were statistically compared by one-way analysis of variance followed by Fisher's Least Significant Difference test, while tumor size was analyzed by the Kruskal-Wallis test, and other parameters were analyzed with the chi-square test. Spearman correlation coefficient tests were used to determine the correlation between the ATA pediatric risk levels and age groups. The recurrence-free survival for each age group was statistically evaluated by the KaplanMeier method. The significance level was set at $P<0.05$.

\section{CONFLICTS OF INTEREST}

None.

\section{FUNDING}

This work was supported by grants from the National Natural Science Foundation of China [Grant No. 81271088 and Grant No. 81670926], and from the Science and Technology Commission of Shanghai Municipality, China [Grant No. 15411950303 and No. 14DZ2260300].

\section{REFERENCES}

1. Hogan AR, Zhuge Y, Perez EA, Koniaris LG, Lew JI, Sola JE. Pediatric thyroid carcinoma: incidence and outcomes in 1753 patients. J Surg Res. 2009; 156: 167-72. doi: 10.1016/j.jss.2009.03.098.

2. Vergamini LB, Frazier AL, Abrantes FL, Ribeiro KB, Rodriguez-Galindo C. Increase in the incidence of differentiated thyroid carcinoma in children, adolescents, and young adults: a population-based study. J Pediatr. 2014; 164: 1481-5. doi: 10.1016/j.jpeds.2014.01.059.

3. Wu XC, Chen VW, Steele B, Roffers S, Klotz JB, Correa $\mathrm{CN}$, Carozza SE. Cancer incidence in adolescents and young adults in the United States, 1992-1997. J Adolesc Health. 2003; 32: 405-15.

4. Welch Dinauer CA, Tuttle RM, Robie DK, McClellan DR, Svec RL, Adair C, Francis GL. Clinical features associated with metastasis and recurrence of differentiated thyroid cancer in children, adolescents and young adults. Clin Endocrinol (Oxf). 1998; 49: 619-28.

5. Lazar L, Lebenthal Y, Steinmetz A, Yackobovitch-Gavan M, Phillip M. Differentiated thyroid carcinoma in pediatric patients: comparison of presentation and course between pre-pubertal children and adolescents. J Pediatr. 2009; 154: 708-14. doi: 10.1016/j.jpeds.2008.11.059.

6. Giuffrida D, Scollo C, Pellegriti G, Lavenia G, Iurato MP, Pezzin V, Belfiore A. Differentiated thyroid cancer in children and adolescents. J Endocrinol Invest. 2002; 25: 18-24.

7. Hay ID, Gonzalez-Losada T, Reinalda MS, Honetschlager JA, Richards ML, Thompson GB. Long-term outcome in 215 children and adolescents with papillary thyroid cancer treated during 1940 through 2008. World J Surg. 2010; 34 : 1192-202. doi: 10.1007/s00268-009-0364-0.

8. Chow SM, Law SC, Mendenhall WM, Au SK, Yau S, Mang O, Lau WH. Differentiated thyroid carcinoma in childhood and adolescence-clinical course and role of radioiodine. Pediatr Blood Cancer. 2004; 42: 176-83. doi: 10.1002/ pbc. 10410 .

9. Handkiewicz-Junak D, Wloch J, Roskosz J, Krajewska J, Kropinska A, Pomorski L, Kukulska A, Prokurat A, Wygoda Z, Jarzab B. Total thyroidectomy and adjuvant radioiodine treatment independently decrease locoregional recurrence risk in childhood and adolescent differentiated thyroid cancer. J Nucl Med. 2007; 48: 879-88. doi: 10.2967/ jnumed.106.035535.

10. Saraiva J, Ribeiro C, Melo M, Gomes L, Costa G, Carrilho F. Thyroid carcinoma in children and young adults: retrospective review of 19 cases. Acta Med Port. 2013; 26: 578-82.

11. Sugino K, Nagahama M, Kitagawa W, Shibuya H, Ohkuwa K, Uruno T, Suzuki A, Akaishi J, Masaki C, Matsuzu K, Ito K. Papillary thyroid carcinoma in children and adolescents: long-term follow-up and clinical characteristics. World J Surg. 2015; 39: 2259-65. doi: 10.1007/s00268-015-3042-4.

12. Kiratli PO, Volkan-Salanci B, Gunay EC, Varan A, Akyuz C, Buyukpamukcu M. Thyroid cancer in pediatric age group: an institutional experience and review of the literature. J Pediatr Hematol Oncol. 2013; 35: 93-7. doi: 10.1097/MPH.0b013e3182755d9e.

13. Markovina S, Grigsby PW, Schwarz JK, DeWees T, Moley JF, Siegel BA, Perkins SM. Treatment approach, surveillance, and outcome of well-differentiated thyroid cancer in childhood and adolescence. Thyroid. 2014; 24: 1121-6. doi: 10.1089/thy.2013.0297.

14. Francis GL, Waguespack SG, Bauer AJ, Angelos $\mathrm{P}$, Benvenga S, Cerutti JM, Dinauer CA, Hamilton J, Hay ID, Luster M, Parisi MT, Rachmiel M, Thompson GB, et al. Management guidelines for children with thyroid nodules and differentiated thyroid cancer. Thyroid. 2015; 25: 71659. doi: 10.1089/thy.2014.0460. 
15. Rivkees SA, Mazzaferri EL, Verburg FA, Reiners C, Luster M, Breuer CK, Dinauer CA, Udelsman R. The treatment of differentiated thyroid cancer in children: emphasis on surgical approach and radioactive iodine therapy. Endocr Rev. 2011; 32: 798-826. doi: 10.1210/er.2011-0011.

16. Demidchik YE, Demidchik EP, Reiners C, Biko J, Mine M, Saenko VA, Yamashita S. Comprehensive clinical assessment of 740 cases of surgically treated thyroid cancer in children of Belarus. Ann Surg. 2006; 243: 525-32. doi: 10.1097/01.sla.0000205977.74806.0b.

17. Vaisman F, Bulzico DA, Pessoa CH, Bordallo MA, Mendonca UB, Dias FL, Coeli CM, Corbo R, Vaisman M. Prognostic factors of a good response to initial therapy in children and adolescents with differentiated thyroid cancer. Clinics (Sao Paulo). 2011; 66: 281-6.

18. Landau D, Vini L, A'Hern R, Harmer C. Thyroid cancer in children: the Royal Marsden Hospital experience. Eur J Cancer. 2000; 36: 214-20.

19. Edge SB, Compton CC. The American Joint Committee on Cancer: the 7th edition of the AJCC cancer staging manual and the future of TNM. Ann Surg Oncol. 2010; 17: 1471-4. doi: 10.1245/s10434-010-0985-4.

20. Vassilopoulou-Sellin R, Klein MJ, Smith TH, Samaan NA, Frankenthaler RA, Goepfert H, Cangir A, Haynie TP. Pulmonary metastases in children and young adults with differentiated thyroid cancer. Cancer. 1993; 71: 1348-52.

21. Frankenthaler RA, Sellin RV, Cangir A, Goepfert H. Lymph node metastasis from papillary-follicular thyroid carcinoma in young patients. Am J Surg. 1990; 160: 341-3.
22. Wada N, Sugino K, Mimura T, Nagahama M, Kitagawa W, Shibuya H, Ohkuwa K, Nakayama H, Hirakawa S, Rino Y, Masuda M, Ito K. Pediatric differentiated thyroid carcinoma in stage I: risk factor analysis for disease free survival. BMC Cancer. 2009; 9: 306. doi: 10.1186/1471-2407-9-306.

23. O'Gorman CS, Hamilton J, Rachmiel M, Gupta A, Ngan BY, Daneman D. Thyroid cancer in childhood: a retrospective review of childhood course. Thyroid. 2010; 20: 375-80. doi: 10.1089/thy.2009.0386.

24. Alessandri AJ, Goddard KJ, Blair GK, Fryer CJ, Schultz $\mathrm{KR}$. Age is the major determinant of recurrence in pediatric differentiated thyroid carcinoma. Med Pediatr Oncol. 2000; 35: 41-6.

25. Demidchik YE, Saenko VA, Yamashita S. Childhood thyroid cancer in Belarus, Russia, and Ukraine after Chernobyl and at present. Arq Bras Endocrinol Metabol. 2007; 51: 748-62.

26. Harness JK, Thompson NW, McLeod MK, Pasieka JL, Fukuuchi A. Differentiated thyroid carcinoma in children and adolescents. World J Surg. 1992; 16: 547-53; discussion 53-4.

27. Jarzab B, Handkiewicz Junak D, Wloch J, Kalemba B, Roskosz J, Kukulska A, Puch Z. Multivariate analysis of prognostic factors for differentiated thyroid carcinoma in children. Eur J Nucl Med. 2000; 27: 833-41. 